19 Revue d'histoire du XIXe siècle

Société d'histoire de la révolution de 1848 et des

révolutions du XIXe siècle

$58 \mid 2019$

Histoire et archéologie : que faire du XIXe siècle ?

\title{
Jean JAURÈS, Euvres, tome 5, Le socialisme en débat, 1893-1897
}

\section{Raymond Huard}

\section{OpenEdition}

\section{Journals}

Édition électronique

URL : https://journals.openedition.org/rh19/6381

DOl : $10.4000 /$ rh 19.6381

ISSN : $1777-5329$

\section{Éditeur}

La Société de 1848

Édition imprimée

Date de publication : 1 août 2019

Pagination : 284-285

ISSN : 1265-1354

Référence électronique

Raymond Huard, « Jean JAURĖS, Fuvres, tome 5, Le socialisme en débat, 1893-1897 », Revue d'histoire du XIXe siècle [En ligne], 58 | 2019, mis en ligne le 01 août 2019, consulté le 07 juillet 2022. URL : http:// journals.openedition.org/rh19/6381; DOI : https://doi.org/10.4000/rh19.6381

Ce document a été généré automatiquement le 7 juillet 2022.

Tous droits réservés 


\title{
Jean JAURÈS, CEuvres, tome 5, Le socialisme en débat, 1893-1897
}

\author{
Raymond Huard
}

\section{RÉFÉRENCE}

Jean Jaurès, Cuvres, tome 5, Le socialisme en débat, 1893-1897, édition établie par Alain Boscus, Paris, Fayard, 2018, 668 p., $35 €$.

1 Avec la parution du tome 5 des CEuvres de Jean Jaurès, la période 1893-1897 est maintenant complètement couverte. Ce tome, excellemment présenté par Alain Boscus, est consacré surtout aux interventions plus théoriques de Jaurès pendant cette période. Le choix des textes qui nous est offert - car il était impossible de reproduire intégralement l'énorme production de Jaurès ${ }^{1}$ - est réparti entre six rubriques thématiques, l'ordre chronologique présidant au classement à l'intérieur de la rubrique. Les trois premières qui forment à peu près la moitié du volume portent sur le socialisme, sa défense contre ses adversaires, les projets d'organisation socialiste. Les réflexions très détaillées de Jaurès sur une future organisation socialiste de la production fondée sur la collectivisation des moyens de production témoignent d'un engagement socialiste profond. Elles sont d'autant plus intéressantes que les socialistes de cette époque répugnent en général à s'y engager. Jaurès veut montrer que le socialisme, loin d'être une utopie, est réalisable et apporte même des solutions aux impasses économiques d'aujourd'hui. En revanche, il reste assez flou sur les moyens d'y parvenir. Une solution pacifique et évolutive est manifestement préférée, mais une grande crise révolutionnaire n'est pas exclue. L'idée que le socialisme n'est au fond que le prolongement dans le domaine de la production et de la répartition des richesses de la démocratie dans l'ordre politique sous-tend cette conviction. Quelques idées-forces dominent sa réflexion. Le socialisme ne doit pas être un étatisme. Il préserve la faculté d'initiative des individus, il peut être « un collectivisme très prudent et très tempéré » conservant tout ce qui n'est pas incompatible avec l'ordre nouveau. Enfin, et c'est à souligner, il doit aussi permettre une augmentation considérable de la production, 
contrairement aux blocages qui affectent la production capitaliste. Si les références à Marx sont assez fréquentes dans les textes à dominante économique, il n'en reste pas moins que, dans la fameuse conférence de décembre 1894 sur "Idéalisme et matérialisme dans la conception de l'histoire ", Jaurès défend l'idée que l'histoire humaine procède d'une double impulsion, d'un côté celle des contradictions du régime économique, de l'autre celle d'une direction intelligible et d'un sens idéal, et donc d'une sorte de synthèse des deux.

2 La deuxième rubrique, elle aussi substantielle ( 160 p.), est consacrée au monde paysan. Jaurès intervient à plusieurs reprises sur ce sujet à la Chambre des députés.

Il a une connaissance approfondie de cette question sous tous ses aspects, qu'il s'agisse des droits de douane - on s'achemine vers le renforcement du protectionnisme -, de la spéculation sur les denrées agricoles, de la répartition de la propriété agricole et de son évolution, de la condition matérielle des différentes catégories de paysans, petits propriétaires, métayers et fermiers ouvriers agricoles et journaliers, des fléaux dont sont victimes les paysans que ce soit l'impôt ou l'usure. Élu d'une circonscription à la fois industrielle et rurale, Jaurès est évidemment conscient de la nécessité de gagner les paysans au socialisme. Il cherche à montrer que le capitalisme progresse aussi à la campagne Il défend à la fois la nationalisation de la terre et la petite exploitation agricole, l'allégement des charges pour les paysans modestes, l'aide qui pourrait leur être apportée sous diverses formes, ainsi qu'une meilleure représentation.

Moins importantes dans le volume sont les réflexions sur l'Université. Elles sont surtout consacrées à la défense de la liberté d'opinion et d'expression des universitaires, face au rapprochement qui, d'après lui, s'esquisse entre la bourgeoisie et l'Église par peur du socialisme. Jaurès combat aussi la volonté de la bourgeoisie de «transformer le régime capitaliste en dogme social » et c'est pourquoi il considère que l'Université peut devenir «l'Église de la pensée libre », mais à condition qu'elle soit « unie à la pensée socialiste ».

La dernière partie du volume porte sur les questions internationales, le rapprochement franco-russe alors d'actualité, la situation de l'Algérie - et notamment la question juive -, et enfin les problèmes de l'Empire ottoman et en particulier les massacres des Arméniens. Jaurès est un peu embarrassé par le soutien populaire manifeste à l'alliance franco-russe qui s'esquisse. Il s'efforce, non sans illusions, de voir dans ce rapprochement «moins l'ébauche d'une nouvelle alliance que la constatation d'une sorte de détente générale ». Il souligne en revanche à juste titre le caractère occulte des accords passés, une politique «faite d'équivoque et de duplicité ». S'il défend avec force les Arméniens menacés par les massacres des Turcs, soulignant au passage les progrès du socialisme chez les Arméniens, il condamne l'inertie de l'Europe (France, Angleterre, Russie) et la complaisance à l'égard du sultan, peut-être renforcée en France par l'influence des porteurs de bons ottomans. C'est sur l'Algérie que ses interventions sont les plus discutables. Certes il remarque que le régime capitaliste favorise la grande colonisation au détriment des indigènes, mais alors qu'un fort mouvement antijuif se développe en Algérie, il se place sur le terrain périlleux d'un vieux monde arabe miné à la fois par les juifs et les colons français, allant très loin à cet égard, jusqu'à envisager l'abolition ou du moins la restriction du décret Crémieux de 1871. Dans l'ensemble des interventions de cette époque, Jaurès fait preuve d'une belle confiance dans le triomphe à venir du socialisme (jusqu'à prévoir son succès dans les dix ans à venir) de sorte que celui-ci apparaît parfois comme l'heureuse solution de tous les problèmes. Mais en revanche, quel plaisir de lire Jaurès dont l'extraordinaire culture (à forte 
composante historique) et le talent oratoire accompagné de réparties savoureuses visà-vis de ses adversaires illuminent bien des pages.

\section{NOTES}

1.

Une liste complète des textes de Jaurès de 1893 à 1897 est donnée en fin de volume. 